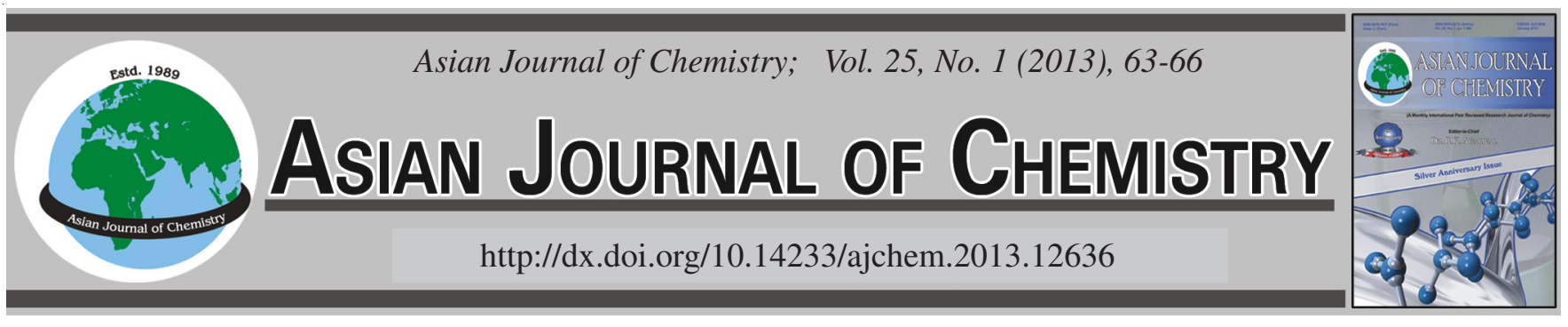

\title{
Cyclic Microwave Synthesis and Photoluminescence of Barium Tungstate Particles Assisted by A Solid-State Metathetic Reaction
}

\author{
Chang Sung Lim
}

Department of Advanced Materials Science \& Engineering, Hanseo University, Seosan 356-706, South Korea

Corresponding author: Tel/Fax: +82 41 6601445; E-mail: cslim@ hanseo.ac.kr

(Received: 26 August 2011;

Accepted: 9 July 2012)

AJC-11821

\begin{abstract}
Barium tungstate $\left(\mathrm{BaWO}_{4}\right)$ particles were synthesized successfully using a solid-state metathetic route assisted by a cyclic microwave irradiation. Well-crystallized $\mathrm{BaWO}_{4}$ particles were formed at $400-600{ }^{\circ} \mathrm{C}$ for $3 \mathrm{~h}$, showing fine and homogeneous morphologies with particle sizes of 1-2 $\mu \mathrm{m}$. The synthesized $\mathrm{BaWO}_{4}$ particles were characterized by X-ray diffraction, Fourier transform infrared spectroscopy and scanning electron microscopy. The optical properties were investigated by photoluminescence emission and Raman spectroscopy.
\end{abstract}

Key Words: Barium tungstate, Cyclic microwave synthesis, Solid-state metathetic reaction, Luminescence, Raman spectroscopy.

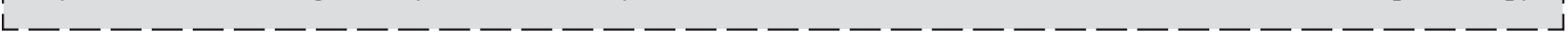

\section{INTRODUCTION}

Metal tungstates are important materials that have a high application potential in the various fields, such as photoluminescence, scintillators, photocatalyst hosts for lanthanideactivated lasers and humidity sensors ${ }^{1,2}$. Metal tungstates of relatively large bivalent cations exist in the so-called Scheelite structure, where the tungsten atom adopts tetrahedral coordination. Barium tungstate $\left(\mathrm{BaWO}_{4}\right)$ has a Scheelite-type crystal structure with lattice parameters of $\mathrm{a}=\mathrm{b}=5.613 \AA$ and $\mathrm{c}=$ $12.720 \AA^{1}$. Barium tungstate particles exhibit blue or green luminescent spectra, which are based on a radiative transition within the tetrahedral $\left[\mathrm{WO}_{4}\right]^{2-}$ group. In general, barium tungstate particles are synthesized by a range of processes, such as co-precipitation ${ }^{3}$, a solvothermal method ${ }^{4}$, spray pyrolysis ${ }^{5}$, a wet chemical method ${ }^{6}$, a mechano-chemical method ${ }^{7}$, a molten salt method ${ }^{8}$, a hydrothermal method ${ }^{9}$, a microwave synthesis ${ }^{10}$ and a solid-state metathetic reaction ${ }^{11}$.

The bulk of the material was heated uniformly resulting in fine particles with a controlled morphology and the product could be fabricated in a green manner without the generation of solvent waste. The solid-state metathetic (SSM) reactions occur so rapidly that the exothermic reaction is essentially used to heat the solid products. Generally, a solid state reaction to synthesize the $\mathrm{BaWO}_{4}$ requires temperatures $>900{ }^{\circ} \mathrm{C}$ for $12 \mathrm{~h}$. Solid-state metathetic reaction assisted by microwave irradiation and post heat-treatment is an essential procedure to synthesize the $\mathrm{BaWO}_{4}$ particles used for the solid-state reactions. Post heat-treatment plays an important role in the well-defined crystallized morphology. Solid-state metathetic synthesis of materials is a simple and cost-effective method that provides a high yield with easy scale up and is emerging as a viable alternative approach for the synthesis of high-quality novel inorganic materials in short time periods ${ }^{12}$.

In present study, $\mathrm{BaWO}_{4}$ particles were successfully synthesized using a solid-state metathetic route assisted by the cyclic microwave irradiation. The characteristics of the solid-state metathetic reaction of $\mathrm{BaWO}_{4}$ particles are discussed in detail based on exothermic reaction accompanying the formation of by-product of $\mathrm{NaCl}$. The synthesized $\mathrm{BaWO}_{4}$ particles were characterized by X-ray diffraction (XRD), Fourier transform infrared spectroscopy (FTIR) and scanning electron microscopy (SEM). The optical properties were examined by photoluminescence (PL) emission and Raman spectroscopy.

\section{EXPERIMENTAL}

$\mathrm{BaCl}_{2} \cdot 2 \mathrm{H}_{2} \mathrm{O}$ and $\mathrm{Na}_{2} \mathrm{WO}_{4} \cdot 2 \mathrm{H}_{2} \mathrm{O}$ of analytic reagent grade were used to prepare the metal tungstate compound. The preparation of $\mathrm{BaWO}_{4}$ was carried out by reacting well-ground mixtures of $\mathrm{BaCl}_{2} \cdot 2 \mathrm{H}_{2} \mathrm{O}$ and $\mathrm{Na}_{2} \mathrm{WO}_{4} \cdot 2 \mathrm{H}_{2} \mathrm{O}$ at a molar ratio of $1: 1$, respectively. The sample mixtures were dried at $100{ }^{\circ} \mathrm{C}$ for $12 \mathrm{~h}$, placed into crucibles and exposed to domestic microwaves (Samsung Electronics Corp. Korea) operating at a frequency of $2.45 \mathrm{GHz}$ and a maximum out-put power of $1250 \mathrm{~W}$ for $40 \mathrm{~min}$. The working cycle of the microwave oven was set between $60 \mathrm{~s}$ on and $30 \mathrm{~s}$ off. The samples were treated with ultrasonic radiation and washed many times with distilled 
water and ethanol to remove the sodium chloride reaction by-product. The samples were dried at $100{ }^{\circ} \mathrm{C}$ in an oven. Heat-treatments of the samples were performed at 400, 500 and $600{ }^{\circ} \mathrm{C}$ for $3 \mathrm{~h}$.

The phase existings in the particles after the solid-state metathetic reactions and heat-treatment were identified by XRD (D/MAX 2200, Rigaku, Japan). FTIR (Nicolet IR200, Thermo Electron corporation, USA) was used to examine the thermal-decomposition behaviour of the solid-state metathetic reaction and the obtained particles over the frequency range, 4000 to $400 \mathrm{~cm}^{-1}$. The microstructure and surface morphology of the $\mathrm{BaWO}_{4}$ particles were observed by SEM (JSM-5600, JEOL, Japan). The photoluminescence spectra were recorded using a spectrophotometer (Perkin Elmer LS55, UK) at room temperature. Raman spectroscopy measurements were performed using a LabRam HR (Jobin-Yvon, France). The 514.5 $\mathrm{nm}$ line of an Ar-ion laser was used as excitation source, the power was kept at $0.5 \mathrm{~mW}$ on the sample.

\section{RESULTS AND DISCUSSION}

Fig. 1 shows XRD patterns of the $\mathrm{BaWO}_{4}$ particles after solid-state metathetic reaction and followed by heat-treatment at $600{ }^{\circ} \mathrm{C}$ for $3 \mathrm{~h}$. All XRD peaks could be assigned to tetragonal phases of $\mathrm{BaWO}_{4}$ with a Scheelite-type structure, which are in good agreement with the crystallographic data of $\mathrm{BaWO}_{4}$ (JCPDS: 43-0646). This means that the tetragonal phases of $\mathrm{BaWO}_{4}$ can be prepared using this solid-state metathetic reaction assisted by a cyclic microwave irradiation. The formations of $\mathrm{BaWO}_{4}$ crystalline phases require heat treatment at $600{ }^{\circ} \mathrm{C}$ for $3 \mathrm{~h}$. The $\mathrm{BaWO}_{4}$ formed had a Scheelite-type crystal structure with lattice parameters of $\mathrm{a}=\mathrm{b}=5.613 \AA$ and $c=12.720 \AA^{1}$. These suggest that solid-state metathetic synthesis is suitable for the growth of $\mathrm{BaWO}_{4}$ crystallites and development of the strongest intensity peaks from the (112), (200) and (312) planes, which were the major peaks of the $\mathrm{BaWO}_{4}$, with some preferred orientation.

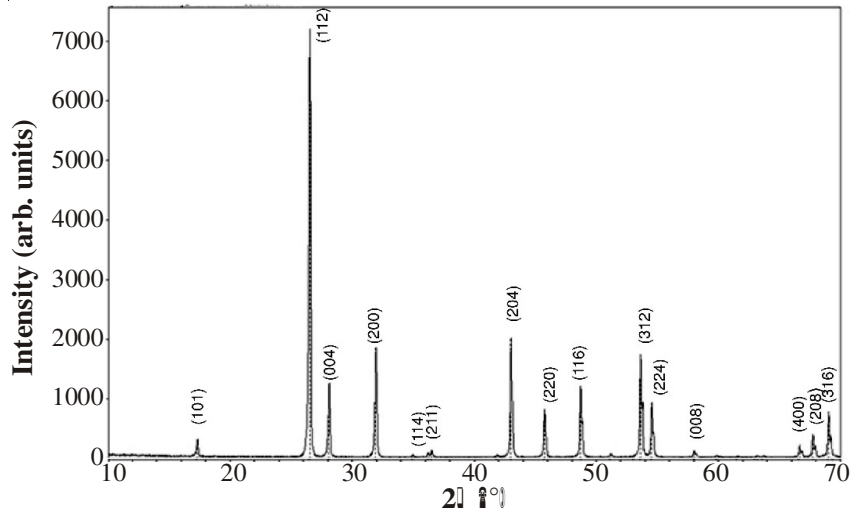

Fig. 1. XRD patterns of the $\mathrm{BaWO}_{4}$ particles after solid-state metathetic reaction and followed by heat-treatment at $600{ }^{\circ} \mathrm{C}$ for $3 \mathrm{~h}$

Fig. 2 shows SEM images of the $\mathrm{BaWO}_{4}$ particles after solid-state metathetic reaction and followed by heat-treatment at (a) $400{ }^{\circ} \mathrm{C}$ for $3 \mathrm{~h}$, (b) $500{ }^{\circ} \mathrm{C}$ for $3 \mathrm{~h}$ and (c) $600{ }^{\circ} \mathrm{C}$ for $3 \mathrm{~h}$. The SEM image of $\mathrm{BaWO}_{4}$ in Fig. 2(c) shows a well-defined and homogeneous morphology with particle sizes of 1-2 $\mu \mathrm{m}$. The structures of the samples prepared at $600{ }^{\circ} \mathrm{C}$ in Fig. 2(c) was much crystallized than that of the samples prepared at 400 and $500{ }^{\circ} \mathrm{C}$ in Fig. 2(a, b). After solid-state metathetic reaction assisted by the microwave irradiation, the reactants are needed to heat at $400,500,600^{\circ} \mathrm{C}$ for $3 \mathrm{~h}$. The solid-state metathetic reaction assisted by the microwave irradiation and post heat-treatment are interdependently essential procedure to synthesize the $\mathrm{BaWO}_{4}$ particles employed for the solid state reactions. These results indicate that the well-defined crystallization depends on the heat-treatment temperatures of the $\mathrm{BaWO}_{4}$ particles. It is noted that the post heat-treatment plays an important role in the well-defined crystallized morphology.
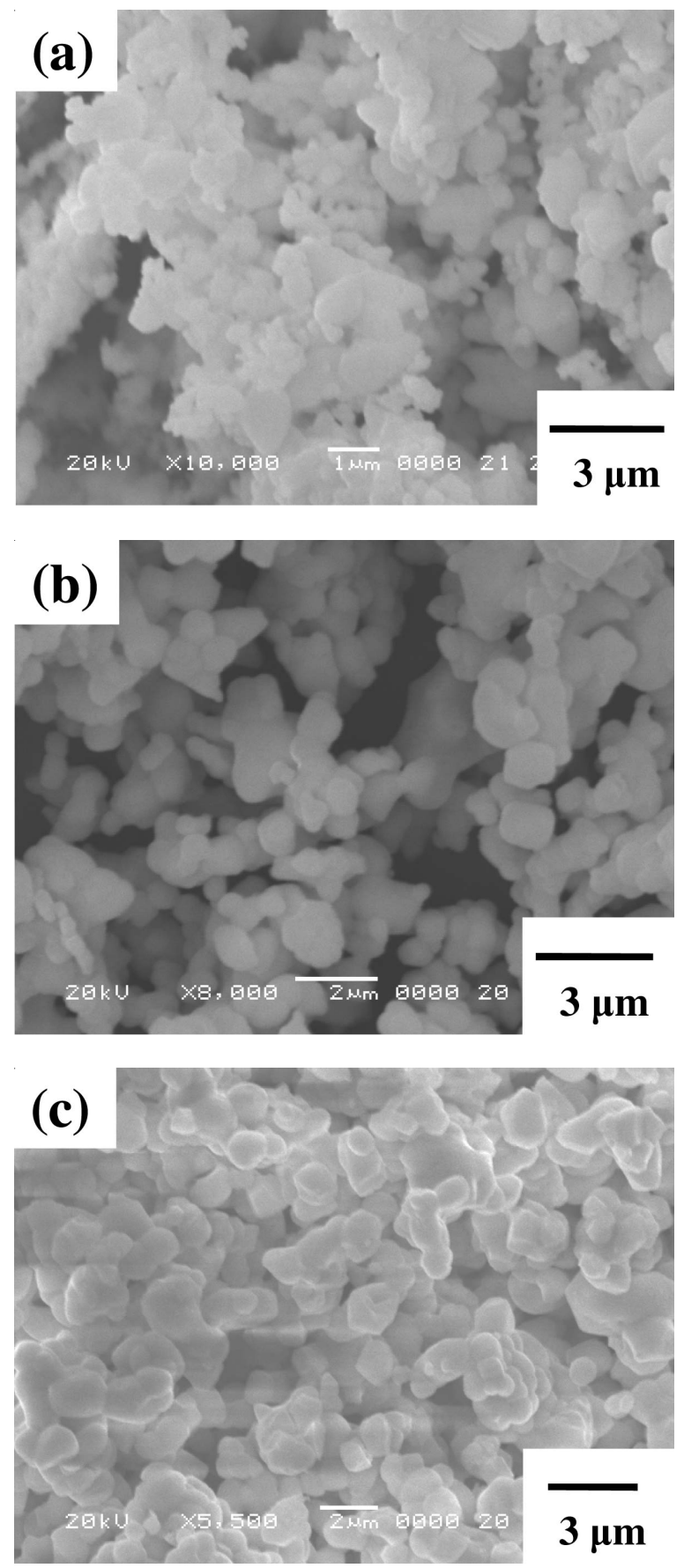

Fig. 2. SEM images of the $\mathrm{BaWO}_{4}$ particles after solid-state metathetic reaction and followed by heat-treatment at (a) $400{ }^{\circ} \mathrm{C}$ for $3 \mathrm{~h}$, (b) $500{ }^{\circ} \mathrm{C}$ for $3 \mathrm{~h}$ and (c) $600{ }^{\circ} \mathrm{C}$ for $3 \mathrm{~h}$ 
The solid-state metathetic reaction assisted by the microwave irradiation of various metal tungstates helps to heat the bulk of the material uniformly resulting in fine particles with a controlled morphology and to fabricate the product in a green manner without the generation of solvent waste. The solidstate metathetic reactions, such as $\mathrm{BaCl}_{2}+\mathrm{Na}_{2} \mathrm{WO}_{4} \rightarrow \mathrm{BaWO}_{4}$ $+2 \mathrm{NaCl}$ involve the exchange of atomic/ionic species, where the driving force is the exothermic reaction accompanying the formation of $\mathrm{NaCl}$ with a high lattice energy ${ }^{12}$. Solid-state metathetic reactions occur so rapidly that the exothermic reaction is essentially used to heat up the solid products. The solid-state metathetic reactions provide a convenient route for the synthesis of metal tungstates, which were obtained in the form of loosely connected submicrometer sized particles at considerably lower temperatures than those usually employed for their synthesis. For tungstate materials to be used for practical applications, control of the particle size distribution and morphology of the particles is needed. The well-defined particle features of the $\mathrm{BaWO}_{4}$ particles synthesized by solidstate metathetic reactions have a control over the morphology of the final particles and can be used for technological applications.

Fig. 3 shows FT-IR spectrum of the obtained $\mathrm{BaWO}_{4}$ particles after solid-state metathetic reaction and followed by heat-treatment at $600{ }^{\circ} \mathrm{C}$ for $3 \mathrm{~h}$ in the wavenumber range, $4000-480 \mathrm{~cm}^{-1}$. A stretching vibration for $\mathrm{BaWO}_{4}$ was detected as a strong $\mathrm{W}-\mathrm{O}$ stretch in the $\left[\mathrm{WO}_{4}\right]^{2-}$ tetrahedra at $816 \mathrm{~cm}^{-1}$. Similar characteristics absorption bands of metal tungstates for the Scheelite oxides having $\mathrm{S}_{4}$ site symmetry in this region have been reported in the literature ${ }^{6}$. The $\left[\mathrm{WO}_{4}\right]^{2-}$ are constituted by four internal modes $\left[\mathrm{v}_{1}\left(\mathrm{~A}_{1}\right), \mathrm{v}_{2}(\mathrm{E}), \mathrm{v}_{3}\left(\mathrm{~F}_{2}\right)\right.$ and $\left.\mathrm{v}_{4}\left(\mathrm{~F}_{2}\right)\right]$ specified as symmetric stretching, symmetric bending, asymmetric stretching and asymmetric bending modes. All these modes are Raman active, whereas only $v_{3}\left(F_{2}\right)$ and $v_{4}\left(F_{2}\right)$ are IR active.

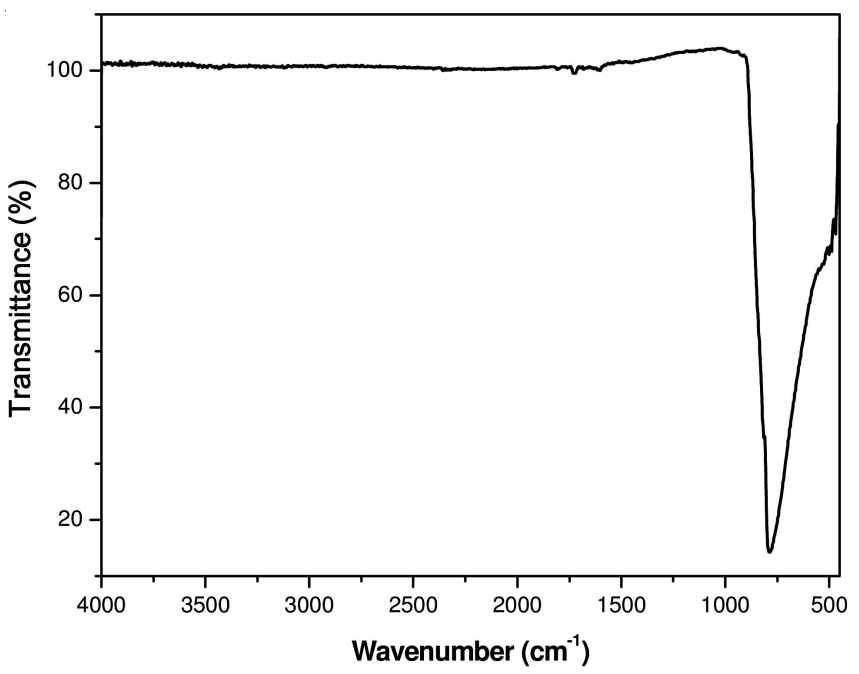

Fig. 3. FT-IR spectra of the $\mathrm{BaWO}_{4}$ particles after solid-state metathetic reaction and followed by heat-treatment at $600^{\circ}$ for $3 \mathrm{~h}$

Fig. 4 shows the photoluminescence emission spectra of the $\mathrm{BaWO}_{4}$ particles after solid-state metathetic reaction and followed by heat-treatment at (a) $400{ }^{\circ} \mathrm{C}$ for $3 \mathrm{~h}$, (b) 500 ${ }^{\circ} \mathrm{C}$ for $3 \mathrm{~h}$ and (c) $600{ }^{\circ} \mathrm{C}$ for $3 \mathrm{~h}$ exited at $250 \mathrm{~nm}$ at room temperature. The emission spectrum of metal tungstates are due mainly to charge-transfer transitions within the $\left[\mathrm{WO}_{4}\right]^{2-}$ complex ${ }^{13,14}$. With excitation at $250 \mathrm{~nm}, \mathrm{BaWO}_{4}$ particles exhibit major photoluminescence emissions in the blue wavelength range of 390-420 $\mathrm{nm}$. The emission spectra of four narrow shoulders at $c a$. 490, 510, 520 and $600 \mathrm{~nm}$ are considered to form by defect structures. The spectrum show broad peaks on which is superimposed considerable several fine structures. The explanation of the narrow shoulders is proposed considering the Jahn-Teller splitting effect ${ }^{15,16}$ on excited states of $\left[\mathrm{WO}_{4}\right]^{2-}$ anion in the $\mathrm{BaWO}_{4}$. This is similar to that reported by Zhan et $a l .{ }^{17}$. The Jahn-Teller splitting effect essentially determines the emission shape of the $\mathrm{MWO}_{4}(\mathrm{M}=\mathrm{Ba}, \mathrm{Ca})$ particles. The additional emission bands can be interpreted by the existence of Frenkel defect structures (oxygen ion shifted to the inter-position with the simultaneous creation of vacancies) in the surface layers of the $\mathrm{BaWO}_{4}$ particles ${ }^{18,19}$. Despite of the somewhat different shapes of the spectra due to the different heat-treatment temperatures, common spectral features can be found. The photoluminescence intensities of the samples prepared at $600{ }^{\circ} \mathrm{C}$ for the $\mathrm{BaWO}_{4}$ particles are much stronger than that of the samples prepared at 400 and $500{ }^{\circ} \mathrm{C}$. These results indicate that the photoluminescence intensity depends on crystallinity of the $\mathrm{BaWO}_{4}$ particles. It is noted that the high crystallinity plays an important role in the improvement of luminescent efficiency. Therefore, it can be considered that the enhancement of photoluminescence intensity with the heat-treatment temperature up to $600{ }^{\circ} \mathrm{C}$ is due to the increment of cystallinity.

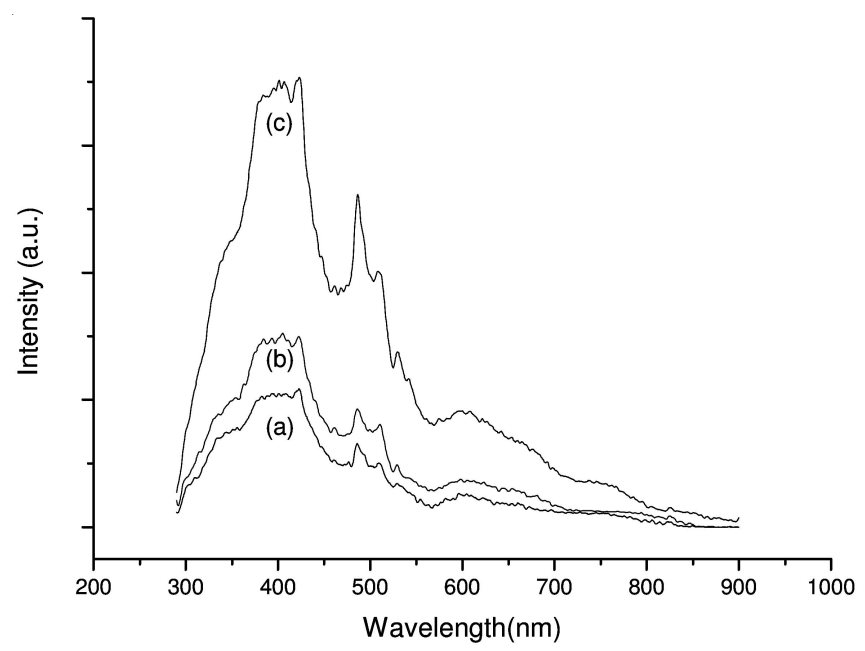

Fig. 4. Photoluminescence emission spectra of the $\mathrm{BaWO}_{4}$ particles after solid-state metathetic reaction and followed by heat-treatment at (a) $400{ }^{\circ} \mathrm{C}$ for $3 \mathrm{~h}$, (b) $500{ }^{\circ} \mathrm{C}$ for $3 \mathrm{~h}$ and (c) $600{ }^{\circ} \mathrm{C}$ for $3 \mathrm{~h}$ exited at $250 \mathrm{~nm}$ at room temperature

Fig. 5 shows Raman spectrum of the $\mathrm{BaWO}_{4}$ particle excited by the $514.5 \mathrm{~nm}$ line of an Ar-ion laser kept at a power of $0.5 \mathrm{~mW}$ on the samples. The vibration modes in the Raman spectra of tungstates are classified into two groups, internal and external. The internal vibrations are related to the $\left[\mathrm{WO}_{4}\right]^{2-}$ molecular group with a stationary mass center. The external vibrations or lattice phonons are associated to the motion of the $\mathrm{Ba}^{2+}$ cation and rigid molecular units. In free space, $\left[\mathrm{WO}_{4}\right]^{2-}$ tetrahedra show $\mathrm{T}_{\mathrm{d}}$-symmetry. The internal Raman modes for 
the $\mathrm{BaWO}_{4}$ particles in Fig. 5 were detected as $v_{1}\left(A_{g}\right), v_{3}\left(B_{g}\right)$, $v_{3}\left(E_{g}\right), v_{4}\left(E_{g}\right), v_{4}\left(B_{g}\right)$ and $v_{2}\left(B_{g}\right)$ vibrations at $925,831,795$, 352,344 and $332 \mathrm{~cm}^{-1}$. The free rotation mode was detected at $189 \mathrm{~cm}^{-1}$ and the external modes were localized at $148 \mathrm{~cm}^{-1}$. The well-resolved sharp peaks for the $\mathrm{BaWO}_{4}$ particles indicate that the synthesized particles are highly crystallized. The type of cations $\left(\mathrm{Ca}^{2+}, \mathrm{Sr}^{2+}, \mathrm{Ba}^{2+}\right)$ can influence on the Raman modes by changing the size of the crystal unit cell and by a covalent cation effect ${ }^{20}$. There is an essential dependence of the bandwidth of the $v_{1}\left(A_{g}\right)$ Raman mode on the peculiarities of the crystal lattice and the type of $\mathrm{Me}^{2+}$ cation in the series of $\mathrm{MWO}_{4}$ $(\mathrm{M}=\mathrm{Ca}, \mathrm{Sr}, \mathrm{Ba}, \mathrm{Pb})$ crystals with a Scheelite structure. Moving in the series of tungstates $\mathrm{Ca}^{2+} \rightarrow \mathrm{Sr}^{2+} \rightarrow \mathrm{Ba}^{2+}$ increases the unit cell and interionic distance inside the molecular group. The degree of covalent bond between the cation and molecular group usually decreases within the series $\mathrm{Ca}^{2} \rightarrow \mathrm{Sr}^{2+} \rightarrow \mathrm{Ba}^{2+}$.

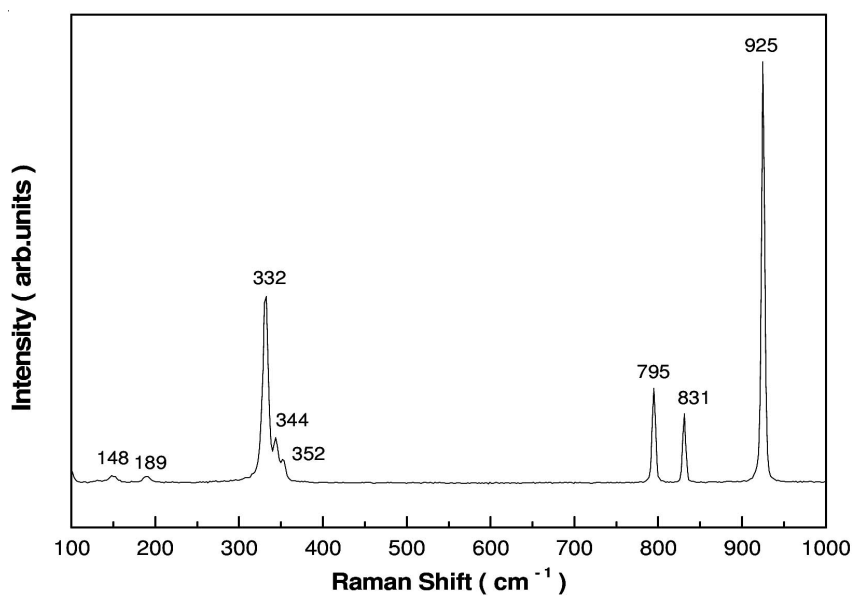

Fig. 5. Raman spectra of the $\mathrm{BaWO}_{4}$ particles excited by the $514.5 \mathrm{~nm}$ line of an Ar-ion laser at $0.5 \mathrm{~mW}$ on the samples

\section{Conclusion}

Barium tungstate $\left(\mathrm{BaWO}_{4}\right)$ particles synthesized using a solid-state metathetic method assisted by a cyclic microwave irradiation were well crystallized at $600{ }^{\circ} \mathrm{C}$, showing a fine and homogeneous morphology with particle sizes of 1-2 $\mu \mathrm{m}$. With excitation at $250 \mathrm{~nm}$, the $\mathrm{BaWO}_{4}$ particles exhibit major photoluminescence emissions in the blue wavelength range of 390-420 nm, accompanying four narrow shoulders considered to form by defect structures. The photoluminescence intensities of the $\mathrm{BaWO}_{4}$ particles prepared at $600{ }^{\circ} \mathrm{C}$ were much stronger than that of the samples prepared at 400 and $500{ }^{\circ} \mathrm{C}$. The internal Raman mode for the $\mathrm{BaWO}_{4}$ particles was detected at $925,831,795,352,344$ and $332 \mathrm{~cm}^{-1}$, the free rotation mode was detected at $189 \mathrm{~cm}^{-1}$ and the external mode was localized at $148 \mathrm{~cm}^{-1}$.

\section{ACKNOWLEDGEMENTS}

This study was supported by Basic Science Research Program through the National Research Foundation of Korea (NRF) funded by the Ministry of Education, Science and Technology (2011-0026911).

\section{REFERENCES}

1. Z. Shan, Y. Wang, H. Ding and F. Huang, J. Mol. Catal. A, 302, 54 (2009).

2. S. Rajagopal, V.L. Bekenev, D. Nataraj, D. Mangalaraj and O.Y. Khyzhun, J. Alloys Compd., 496, 61 (2010).

3. T. Thongtem, S. Kungwankunakorn, B. Kuntalue, A. Phuruangrat and S. Thongtem, J. Alloys Compd., 506, 475 (2010).

4. A.J. Rondinone, M. Pawel, D. Travaglini, S. Mahurin and S. Dai, J. Colloid. Interface Sci., 306, 281 (2007).

5. S. Thongtem, S. Wannapop and T. Thongtem, Trans. Nonferr. China, 19, s100 (2009).

6. G. Zhang, R. Jia and Q. Wu, Mater. Sci. Eng. B, 128, 254 (2006).

7. D. Rangappa, T. Fujiwara, T. Watanabe and M. Yoshimura, J. Electrochem., 17, 853 (2006).

8. Y. Wang, J. Ma, J. Tao, X. Zhu, J. Zhou, Z. Zhao, L. Xie and H. Tian, Mater. Sci. Eng. B, 130, 277 (2006).

9. K. Eda, Y. Kato, Y. Ohshiro, T. Sugitani and M.S. Whittingham, J. Sol. State Chem., 183, 1334 (2010).

10. J.T. Kloprogge, M.L. Weier, L.V. Duong and R.L. Frost, Mater. Chem. Phys., 88, 438 (2004).

11. P. Parhi, T.N. Karthik and V. Manivannan, J. Alloys Compd., 465, 380 (2008).

12. S. Das, A.K. Mukhopadhyay, S. Datta and D. Basu, Bull. Mater. Sci., 32, 1 (2009).

13. D.A. Spassky, S.N. Ivanov, V.N. Kolobanov, V.V. Mikhailin, V.N. Zemskov, B.I. Zadneprovski and L.I. Potkin, Radiat. Measur, 38, 607 (2004).

14. G.Y. Hong, B.S. Jeon, Y.K. Yoo and J.S. Yoo, J. Electrochem. Soc., 148, H161 (2001).

15. Y. Toyozawa and M. Inoue, J. Phys. Soc. Jpn., 21, 1663 (1966).

16. E.G. Reut, Izv. Akad. Nauk SSSR, Ser. Fiz., 43, 1186 (1979)

17. Y. Zhang, N.A.W. Holzwarth and R.T. Williams, Phys. Rev. B, 57, 12738 (1998).

18. J. van Tol and J.H. van der Waals, Mol. Phys., 88, 803 (1996).

19. V.B. Mikhailik, H. Kraus, D. Wahl and M.S. Mykhaylyk, Phys. Status Solid B, 242, R17 (2005).

20. T.T. Basiev, A.A. Sobol, P.G. Zverev, L.I. Ivleva, V.V. Osiko and R.C. Powell, Opt. Mater., 11, 307 (1999). 